\title{
HYBRID OF SOLAR PHOTOVOLTAIC AND WIND ENERGY TO SUPPLY AN ISOLATED LOAD
}

\author{
G. E. M. Aly and A. A. El-Zeftawy
}

Faculty of Engineering, Menoufia University, Shebin EI-Kom, Egypt

\section{ABSTRACT :}

This work aims to determine the optimal hybrid of an autonomous generation system of renewable energy sources (RESs) to supply an isolated load. This system includes solar photovoltaic generators, windgenerators and energy storage units. A technical and economical model is introduced here to optimize the combined energy of this hybrid system. This model depends on the hourly solar radiation, wind speed and the load demand at the considered site, in addition to the economical parameters and operational constraints of the aforementioned RESs.

The suggested model is applied numerically with the nonlinear programming for planning photovoltaic and wind energy systems to supply an isolated load in remote area of Egypt. Also, the capacity of energy storage units to ensure the continuity of the power supply used is determined and optimized by a load management technique. The combined energy of this hybrid system is optimized from economical point of view.

\section{1- INTRODUCTION :}

Electric generation of renewable energy sources appears increasingly attractive because the high cost of fossil fuels. Also, these sources are more attractive to supply isolated loads in rural and remote areas $[1,2]$. The main types of these RESs pertaining the meteorological conditions for many of the world countries as well as Egypt are solar and wind energies.

Maunscript Received From Dr. (i.F.M. Aly and Dr. A.El-Zeftawy. on 1/12/1998.

Accepted on : 22/12/1998.

Engineering Researcth Bulletin, Vol. 22, No. 1, 1999.

Minufya University, Faculty of Engineering, Shebin El-Kom, ECYPT, iss 1110-1180 
However, there are several difficulties associated with the conversion of these energies. The intermittency of the solar radiation and wind speed is the more serious phenomenon of these difficulties. Not only the reduced times of those sources but also their variation does not match with the distribution time of the demand. To overcome some of these problems a storage facility can be used to compensate the mismatch between the load and energy generation [3]. Also, the combined use of wind and solar energy conversion systems can provide significative advantage as the fluctuations of these sources are not in phase, thus decreasing the storage capacity required [4].

A great number of autonomous generation systems have been installed at many of the world countries. These systems consists mainly of diesel units and have relatively high operation costs due to the high price and transmission expences of the fuel used. The available wind or/and solar energy in these countries makes it attractive to consider RESs as expansion alternatives in the aspect of reducing both of operational cost and pollution problems. But, collection and validation of meteorological data, modelling of the stochastic nature of renewable's output and the correlation between the meteorological data and loads are crucial for the resulting optimal expansion planing of these systems. In pervious publications $[5,6]$, number of computer packages have been introduced for solving these problems and planning RESs with conventional generation systems. On the other hand, an algorithm for the determination of the optimal size and number of wind energy conversion systems operating in parallel with a conventional system was presented in Ref. [7].

In this work, a proposed model has been introduced to develop the availability of solar and wind energy systems to meet an isolated load. This model is used with the solar and wind data collected at an Egyptian site for developing the availability of power generation of each source to supply the load demand at the considered site. Moreover, the combination energy of these sources is optimized economically.

\section{2- TECHNICAL AND ECONOMICAL MODEL :}

The generation system under study consists of wind generators (WEGs), solar photovoltaic generators (PVGs) and energy storage units (ESUs). The ESU is represented here by a storage battery and can be changed from WEG or/and PVG. The storage battery is used for keeping the energy balance and regulating the system reliability. Fig. 1 shows the line diagram of this hybrid system. 
The optimum energy combination of WEG and PVG is obtained as a function of solar radiation and wind speed at the considered site. The output of a PVG is given as [8]:

Since

$$
P_{v(i, j)}=m * \eta_{c} * \eta_{p} * V_{c(i, j)} * I_{c(i, j)}
$$

$$
\begin{aligned}
& V_{c(i, j)}=24-2.1 \times 10^{-3}\left(T_{c(j)}-25\right) \\
& I_{(i, j)}=1.35 H_{(i, j)}+0.5 \times 10^{-3}\left(T_{c(j)}-25\right)
\end{aligned}
$$

The output of the WEG in the range of wing speed of $u_{c}<u_{(i, j)}<u_{0}$ is given by :

where,

$$
P_{w(i, j)}=K_{w g} * P_{g}\left(1+u_{(i, j)} / u_{g}\right)
$$

The hourly output of generation system through the year months may be expressed as follows:

$$
\mathrm{P}_{(\mathrm{i}, \mathrm{j})}=\mathrm{P}_{\mathrm{v}(\mathrm{i}, \mathrm{j})}+\mathrm{P}_{\mathrm{w}(\mathrm{i}, \mathrm{j})}
$$

The mass balannce equation of the generation system output and load demand can be stated as:

$$
P_{L(i, j)}=P_{(i, j)}+P_{s(i, j)}
$$

The optimal combination energy from the hybrid systent to minimize the total investment cost over the study period, i.e. to minimize:

$$
\begin{array}{ll} 
& F_{\mathrm{T}}=\Sigma_{\mathrm{N}}\left(\mathrm{F}_{\mathrm{v}}+\mathrm{F}_{\mathrm{w}}+\mathrm{F}_{\mathrm{s}}+\mathrm{F}_{\mathrm{o}}\right) \\
\text { Since; } & \mathrm{F}_{\mathrm{o}}=\mathrm{F}_{\mathrm{ov}}+\mathrm{F}_{\mathrm{ow}}+\mathrm{F}_{\mathrm{ob}}
\end{array}
$$

The total investment cost for the WEG, PVC and ESU during a considered period may be deduced as a function of the energy supplied from each source and the unit energy cost of these sources as follows:

Since,

$$
\begin{aligned}
& F_{v}=E_{v} * U E G_{v} \\
& F_{w}=E_{w} * U E C_{w} \\
& F_{s}=E_{s} * U E C_{s}
\end{aligned}
$$

where RF, is the capital cost recovery factor and deduced as a function of the interest rate (r) and the life-time of the system (n) as [3]:

$$
R F=r(1+r)^{n} /\left[(1+r)^{n}-1\right] .
$$




\section{3- CASE STUDY :}

A hybrid system of solar photovolatic generator ( $P V G)$, windgenerator (WEG) and storage battery (ESU) is employed to supply an isolated load at El-kharga Oasis in the west disert of Egypt. Fig. 2 shows the average yearly daily load curve in this site. Also, this figure illustrates the categories of this load. These categories are pumping load (90\%) and residential load $(10 \%)$.

The meteorological data at El-Kharga site $\left(25.45^{\circ} \mathrm{N}\right)$ are collected over ten years and used with the proposed model, section 2, for obtaining the optimum combination of PVG, WEG and ESU to achieve the best use of energy available to meet the load demand. The stochastic nonlinear programming technique [9] is used here to solve this problem tacking the following constraints into consideration:

1 -One or more of $100 \mathrm{KW}$ wind-generator is assumed to be used.

2-For each hour the power from WEG, PVG and ESU equals to load demand.

3-The capacity of ESU is restricted by the actual output of WEG and PVG through the day hour.

4-The charge source for ESU is restricted by the permitted loading on WEG and PVG, in addition to the economy of these generator.

5-The percentage limitation of power capacity of WEG and PVG is restricted by the capital investment. The economical parameters of PVGs and WEG are taken from references [8] and [10].

Fig. 3 shows the hourly output of the PVG and WEG through a day of different year months. The storage energy required to satisfy the load demand is deduced from the correlation between the load demand and PVG \& WEG outputs as depicted in Fig. 4. This figure illustrates also the combination energy of the hybrid system to meet the daily load demand of different year months.

The results of these figures concluded that:

1-The PVG's array size of $1255 \mathrm{~m}^{2}$ with one WEG and ESU of $300 \mathrm{~A} . \mathrm{h}$ capacity are required.

2-most of the diurnal load demand through the year months is supplied from PVG.

3-The capacity of ESU is decreased with increasing the WEG output through the year months.

4-About $65 \%$ of ESU capacity is charged from PVG.

5- The total annual cost of the hybrid system is L.E. 131200. 
A load management technique is suggested here to minimize the capacity of ESU which represented the high portion cost of the study hybrid system. This technique is based on operating water pumps through the periods of high solar radiation or / and more effective wind speed. Fig. 5 shows them modified daily load curve wit using this load management technique. Fig. 6 gives the energy combination of the hybrid system for this case. This figure concluded that:

I-The capacity of ESU is decreased by about $80 \%$ than that of first case (Figure 4).

2-The total annual cost of combined energy of the hybrid system is L.E. 102543.

3-More than $90 \%$ of ESU capacity is charged from WEG.

\section{CONCLUSIONS :}

A technical and economical model is introduced to determine the optimal hybrid of an autonomous generation system. This system includes solar photovolatic generator, wind generators and energy storage units (ESUs). Also, a load management technique is suggested to minimize the capacity of ESUs. The proposed model is applied numerically to develop the optimal combination oh generated energy for hybrid system to suit the isolated load at an Egyptian site. The remarkable results of this application are summarized as:

1-A $100 \mathrm{KW}$-wind energy system, $1255 \mathrm{~m}^{2} \mathrm{PV}$ array size and $300 \mathrm{~A} . \mathrm{h}$ battery storage are required to supply the load demand, with about $131200 \mathrm{~L} . \mathrm{E}$ total annual cost.

2-The proposed load management decreases the ESU capacity by about $80 \%$ and decreases the total annual cost of combined energy of the hybrid system by $21.8 \%$.

3-The diurnal load demand through the year months is fed by PVG, while the high portion of ESU capacity is charged from WEG at using the proposed load management technique.

\section{NOMENCLATURE :}

$\mathrm{V}_{(\mathrm{i}, \mathrm{j})}, \mathrm{I}_{(\mathrm{i}, \mathrm{j})}$ : the hourly voltage and current of a PV module through the $\mathrm{j}$ th month respectively.

$\mathrm{H}_{(i, j)}$ :the hourly insulation received on the PV module through the $\mathrm{j}$ th month.

$P_{g} \quad$ :the rated power of the studied wind-generator.

$P_{L(i, j)}$ :the load demand through the $i$ th hour of the $j \underline{\text { th }}$ month.

$\mathrm{P}_{\mathrm{s}(\mathrm{i}, \mathrm{j})} \quad$ :the hourly power supplied from the energy storage unit (ESU) through the $\mathrm{j}$ th month.

$E_{v a}, E_{\mathrm{wa}} \& E_{\mathrm{sa}}$ : the annual energy output of PVG and ESU respectively. 
$E_{\mathrm{v}}, E_{\mathrm{w}} \& E_{s}:$ the energy supplied to the load through the considered period from $P V G, W E G$ and ESU respectively.

$\mathrm{F}_{\mathrm{v}}, \mathrm{F}_{\mathrm{w}} \& \mathrm{~F}_{\mathrm{s}}$ : the total investment of PVG, EWG and ESU during the considered period respectively.

$\mathrm{F}_{0} \quad$ :the total operation cost of the hybrid system during the considered period respectively.

$F_{o v}, F_{o w} \& F_{o s}$ :the operation and maintenance costs of OVG, WEG and ESU the considered period respectively.

$\mathrm{CC}(\mathrm{PV}), \mathrm{CC}(\mathrm{WG}) \& \mathrm{CC}(\mathrm{BS})$ :the capital cost of PVG, WEG and ESU respectively.

$\mathrm{UEG}_{\mathrm{v}}, \mathrm{UEG}_{\mathrm{w}}$ \&UEC $_{\mathrm{s}}$ : the unit energy cost of PVG, WEG and ESU respectively.

$U_{c}, U_{g} \& U_{0}$ :the cut-in, rated and cut-out wind speed of the considered wind-generator.

$U_{(i, j)} \quad$ :the average hourly wind speed through the $\mathrm{j}$ th month.

$\mathrm{K}_{\mathrm{wg}}$ :the wind-generator conversion factor.

$\mathrm{C}_{\mathrm{p}} \quad$ :the performance coefficient.

A : the area swept of the wind rotor.

$\rho \quad$ :the air density.

m :number of modules required for PVG..

$T_{c(j)} \quad$ :the average temperature through the $\mathrm{j}$ th month.

$\eta_{c}, \eta_{p}$ :the efficiencies of PV array and power conditioner respectively.

$\eta_{\mathrm{T}}, \eta_{\mathrm{g}}$ :the efficiencies of wind turbine and generator respectively.

\section{REFERENCES :}

1. Travers, D.L. and Kaye, P.J.; "Modelling and Optimization of Storage and Load Management in Remote Area Power Suppliers", Proceedings of the 24th Universities Power Engineering Conference, UPEC'92, PP. 448-451.

2. El-Zeftawy, L.A.; "Economic Worth of Photovoltaic Systems for Rural and Remote Area Applications" Scientific Bulletin of Faculty of Engineering and Technology, Sues Canal University, Vol. 5, No. 2, 'June 1993, PP. 186-198.

3.Johnson, G.L.; "Wind Energy Systems", Handbook, Prentice-Hall, Inc., 1985.

4. Sorensen, B.; "On the Fluctuations Power Generation of Larg Wind Energy Converters, with and without Storage Facility", Solar Energy, Vol. 20, January, 1978.

5. "Wien Automatic System Planning Pakage (WASP)-A Computer Code for Power Generating System Expansion Planning", IAEA, Viena, 1980. 
6. Kabouris, J. and Contaxis, G.C.; "Autonomous System Expasion Planning Considering Renewable Energy Sources-A Computer Pakage", IEEE, Tran. on Energy Conversion, Vol. 7, No. 3, September 1992, PP. 374-381.

7. Christakis, D.G.; "An Algorithm for the Optimal Design of Renewable Sources Systems", 2nd European Symposium of Soft Energy Sources and Systems at the Local Level, Chania, October, 1989.

8. El-Zeftawy, A.A; "Conversion of Solar Energy to Electricity in Egypt", Proceedings of Second International Conference on Engineering Research, ICER-95, Port-Said, Egypt, December 19-21, 1995, PP. 383-393.

9. Fahmy, F.H.; "Hierarchical Control of Multi-Area Nonlinear Stochastic System with Application to Solar "Proceedings of Third Cairo International Conference on Renewable Energy Sources, Cairo, Egypt, Dec. 29, 1992/Jan. 2, 1993, PP. 75-82.

10.Rowe, E.D.; "Renewable Energy: Target for the Year 2000", IEEE Spectrum, February, 1982. 


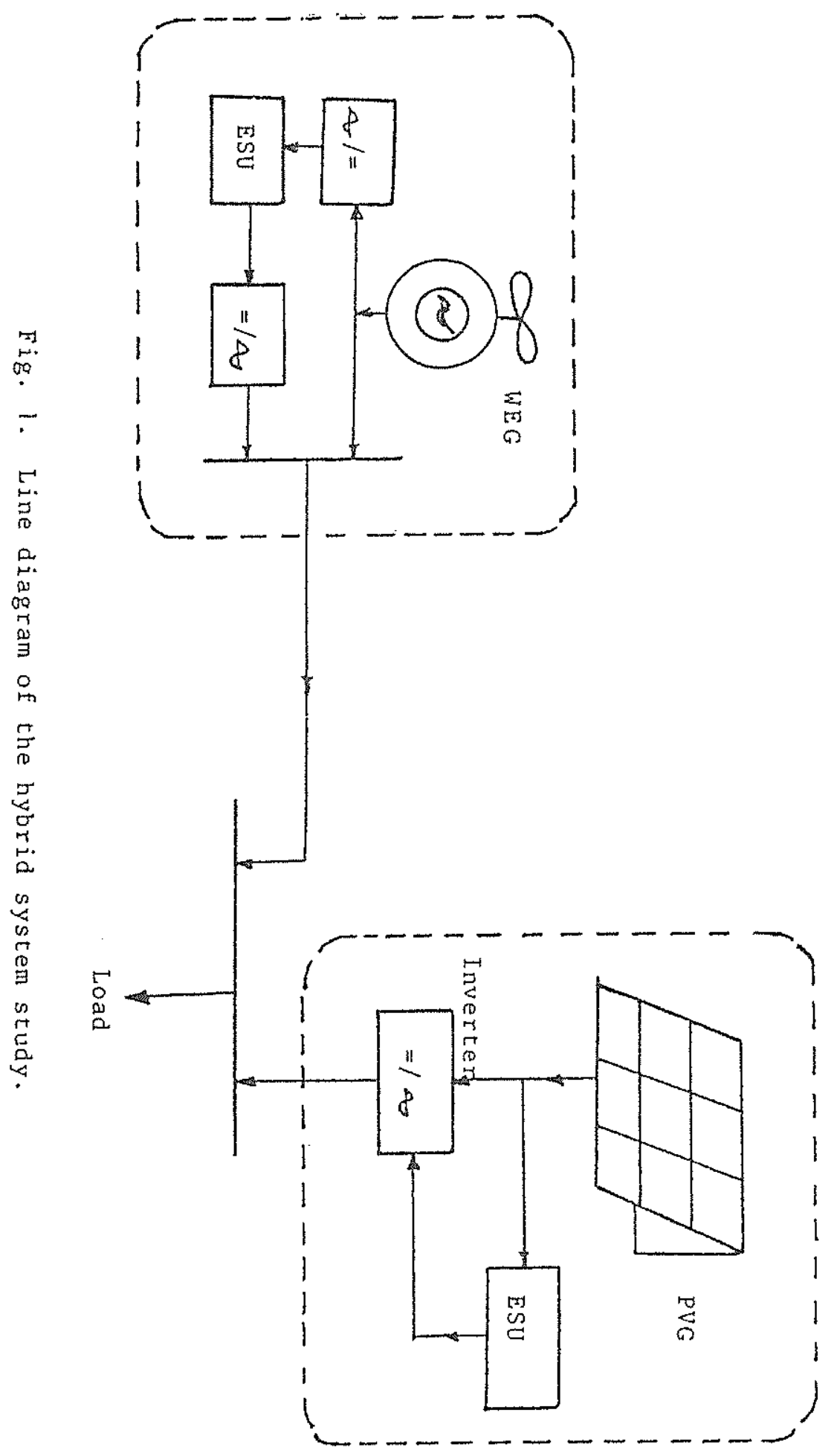




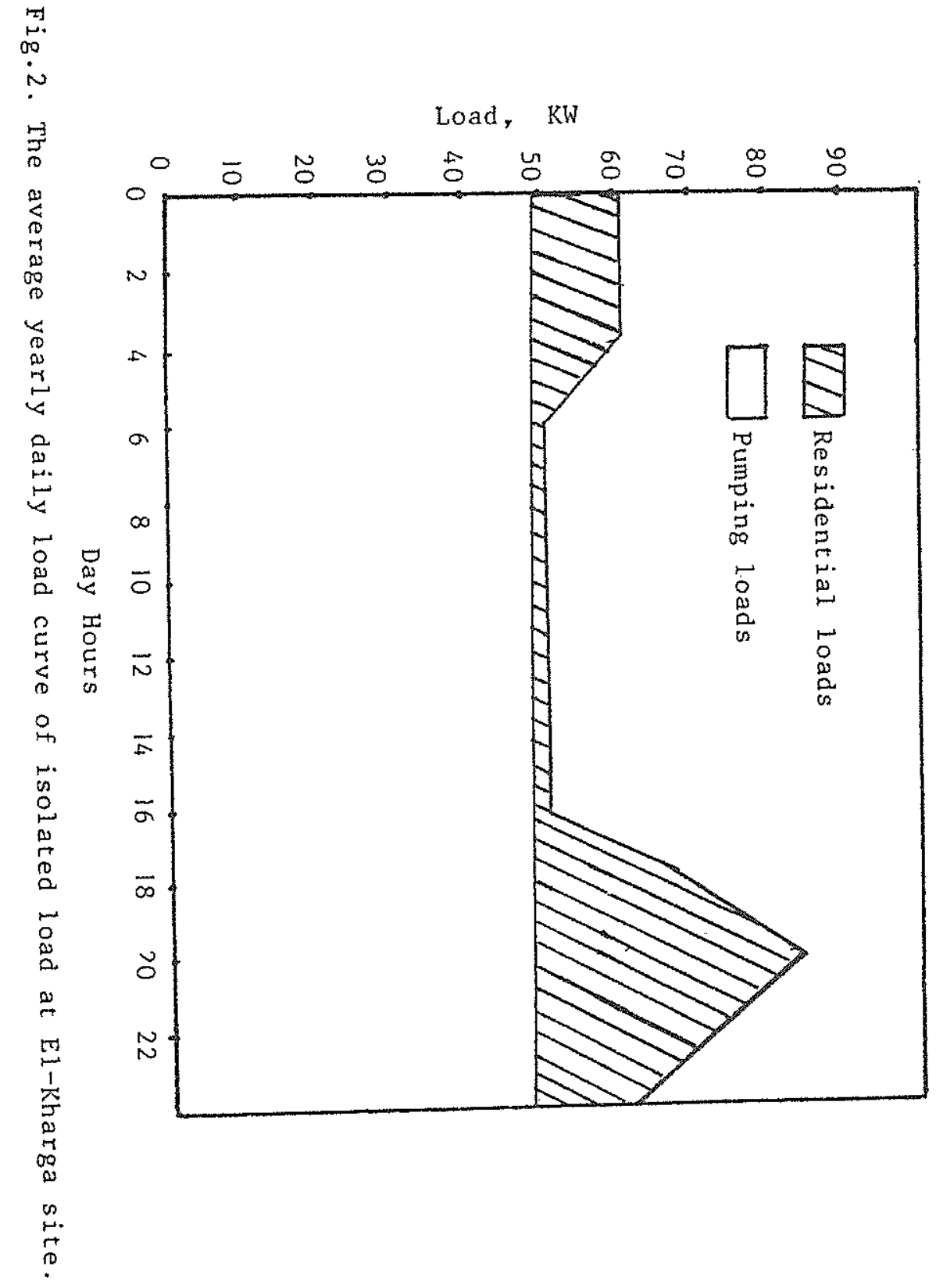



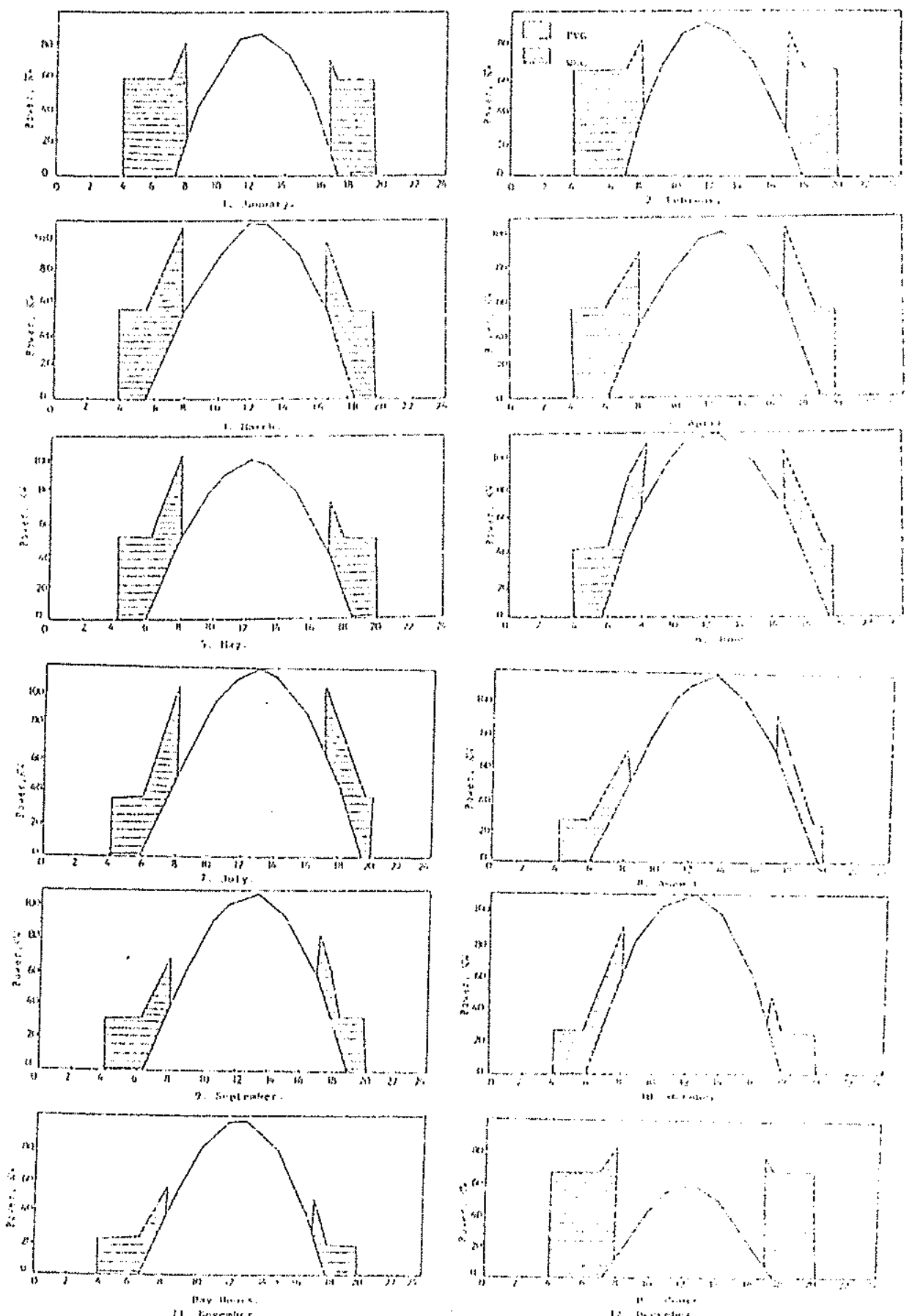

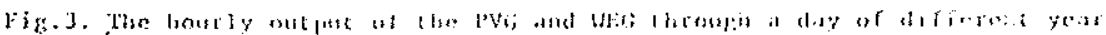
imsutist. 

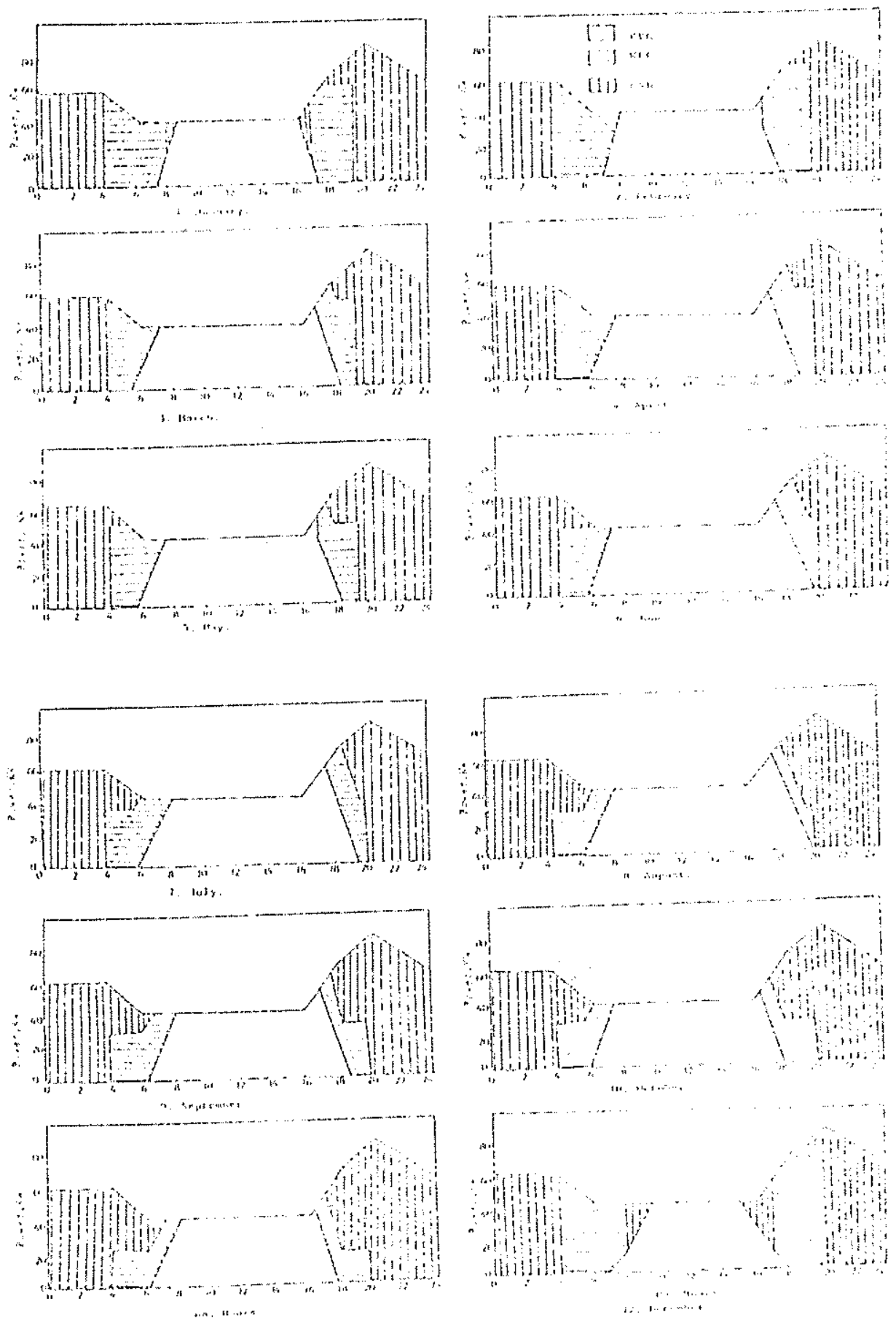

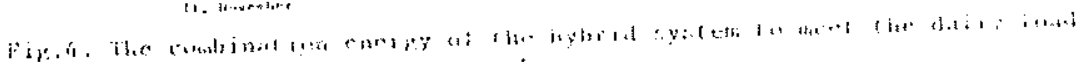

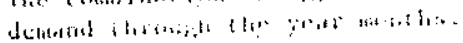




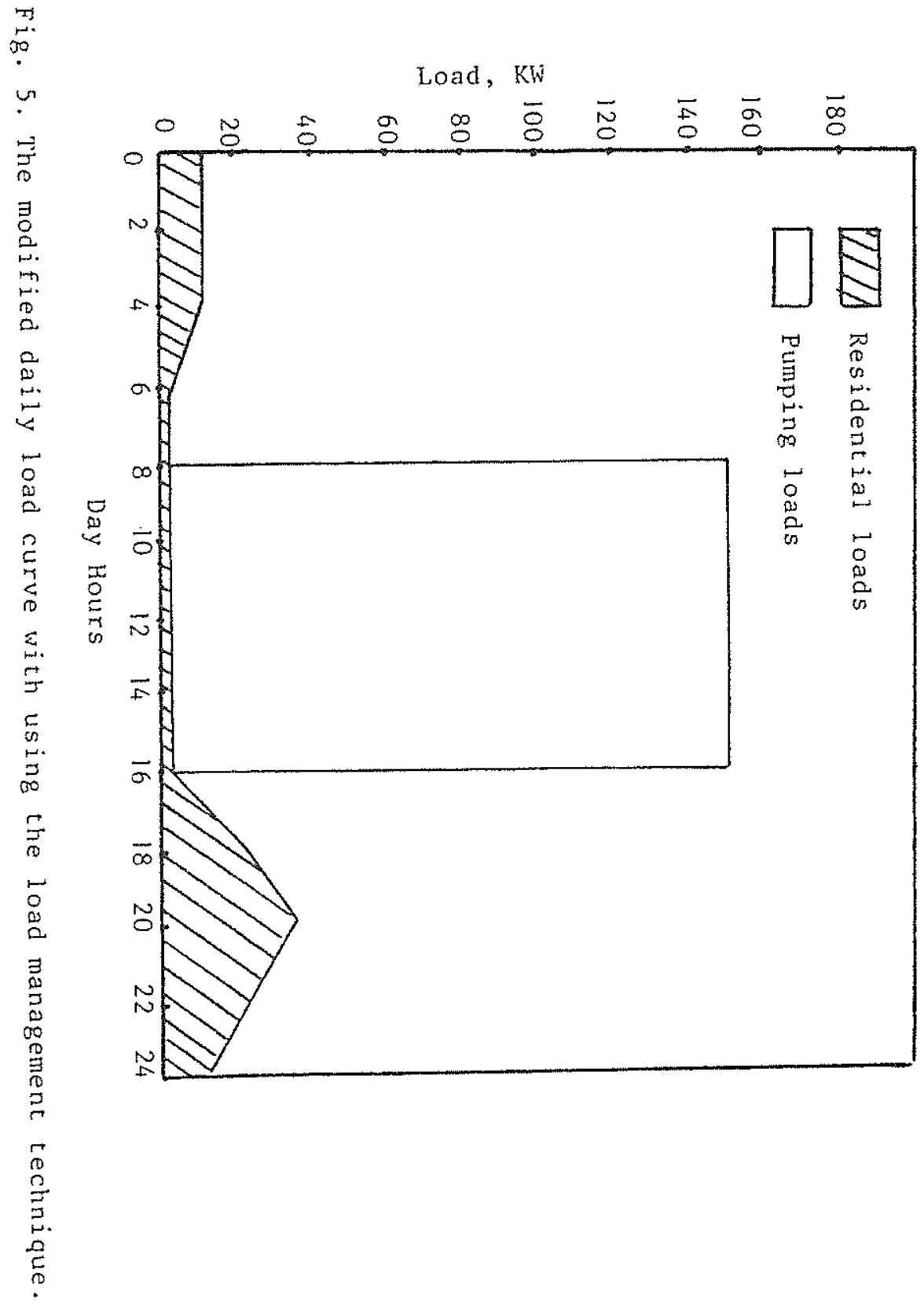



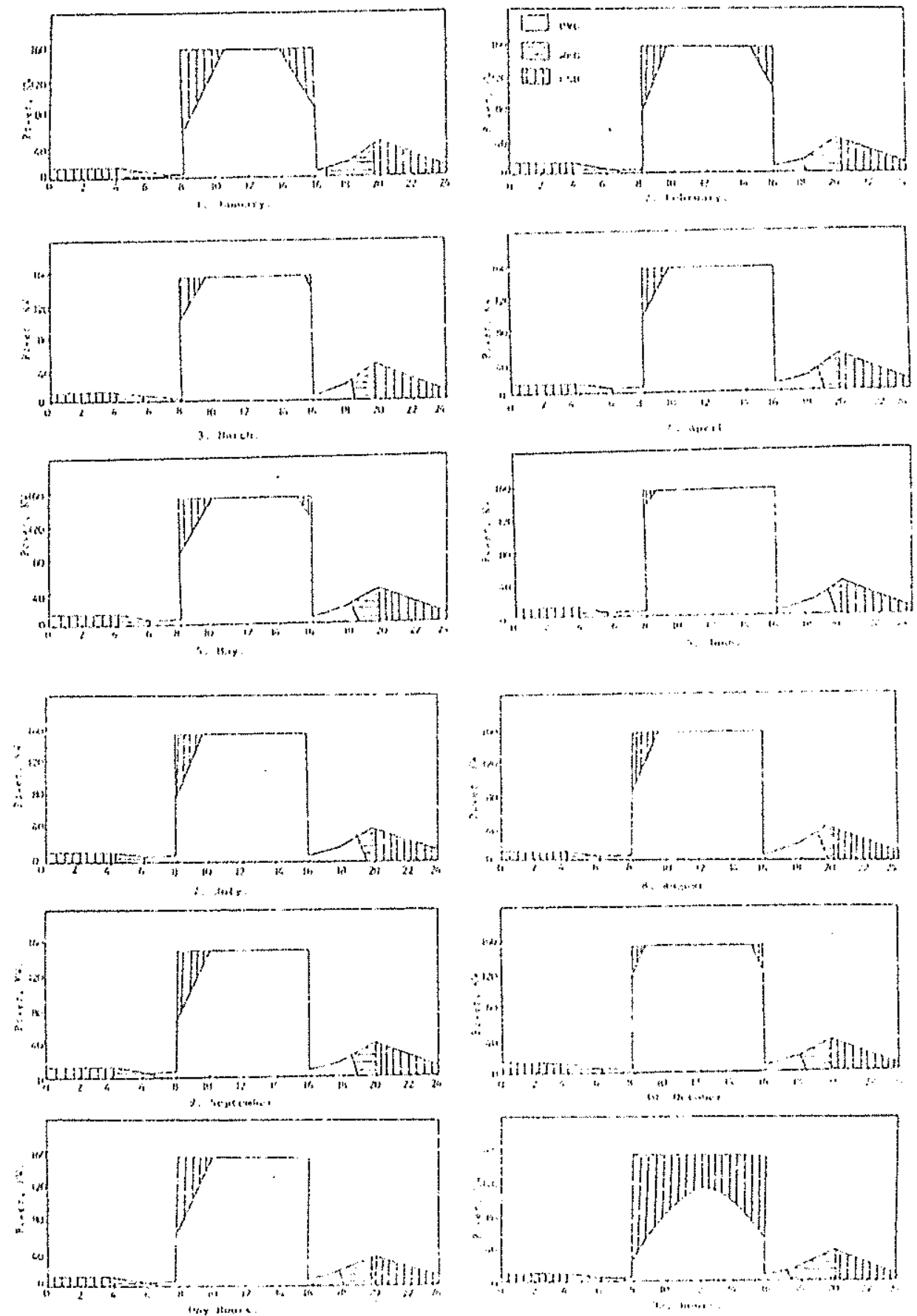

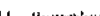

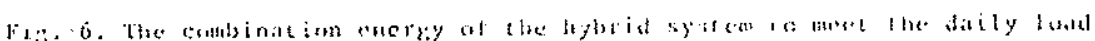

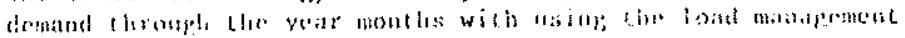

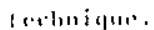




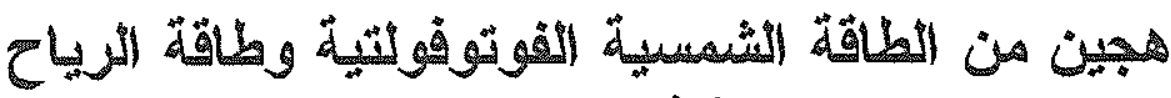

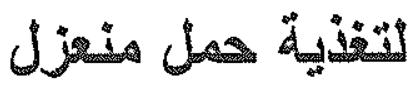

أ.د/ عاطف عبد المكيم الزفقتاوى

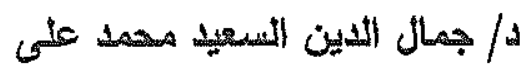

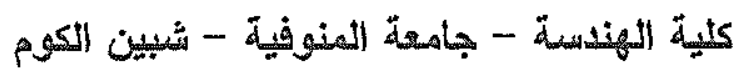

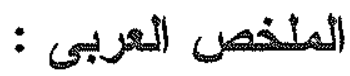
يهدف هذا البحث إلى إيجاد طريقة مثلى لـفاضلة الطاقة الناتجة مــن منظومسـة نوليــد

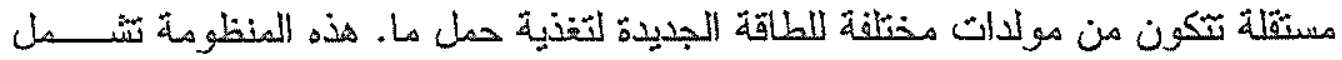
مولدات الطاقة الشمسية القونوفولتية وطاقة الرياح ووحدات لتخزين الطاقة (بطاريات).

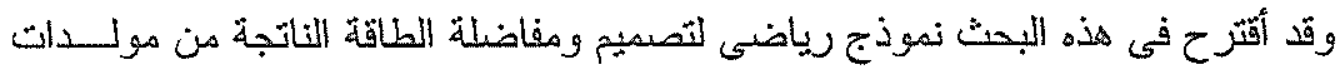

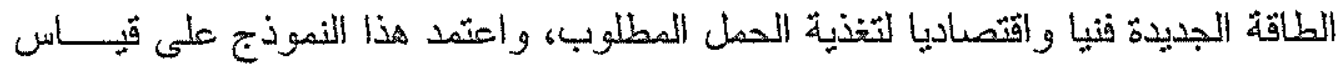

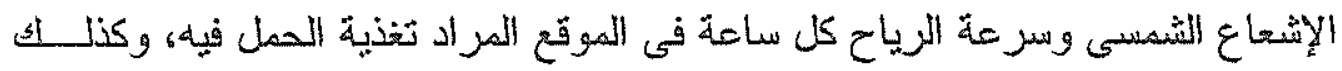
اقتصاديات مولدات الطاقة الجديدة المستخدمة.

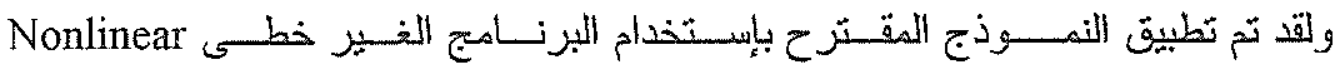

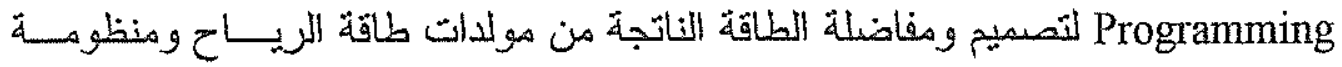

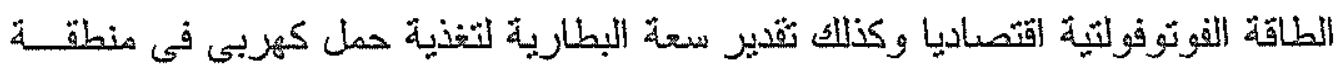
نائية هن مصر.

كما اقترحت طريقة لتبير الحمل Load Management التقليل سعة البطارية المطلوبــة حيث انها تنظل الجزء الأكبر فى اقتصاديات منظومة الثوليد المقترحة من مولدات الطاقة

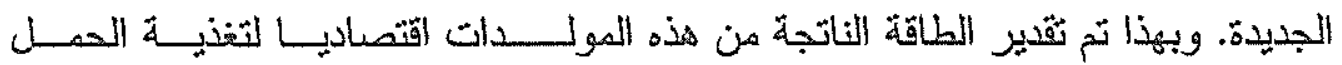
المطلوبب. وقد أوضحت النتائج أن قدرة مولد الطاقة اللفوتوفولتية المطلوب ك الك.وات مع مولــد

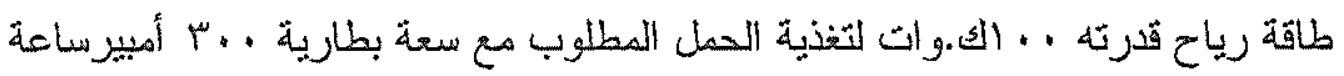

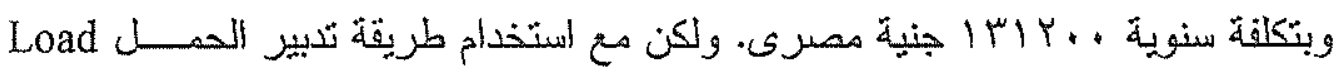

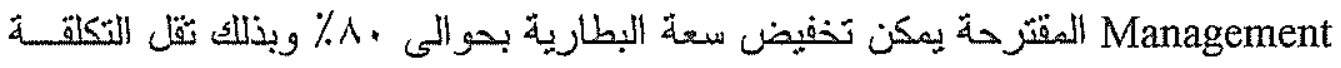

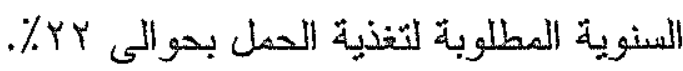

